\title{
MANCHESTER 2014: INSIGHTS AND INSPIRATION
}

\section{W}

ith less than six months to go until the British Dental Conference and Exhibition next April it is definitely not too early to start planning a team trip to Manchester. Booking is already open and many speakers, sessions and features have already been confirmed as part of a programme that promises to offer insights and inspiration to all.

\section{A packed programme}

Topping the bill at the Manchester Central Convention Complex are the 60+ Conference Pass sessions, all of which will take place in the venue's permanent lecture theatres including the 1,600 seat Exchange Hall and the 800 seat Exchange Auditorium. A wide variety of subject matter will be covered over the course of three days, much of which will interest the whole team.

\section{IDDENTAL DCONFERENCE \& MEXHIBITION 2014}

\section{0-12 April | Manchester}

On Thursday 10 April Vicki Jones, Consultant in Special Care Dentistry and Clinical Director of Aneurin Bevin Health Board, will discuss the challenges of treating patients with dementia whilst Keith Horner, Professor of Oral and Maxillofacial Imaging at the University of Manchester, will tell you what you need to know about the new radiology guidelines. Also on Thursday Dento-Legal Adviser and FGDP Board Member Andrew Hadden will talk through the new GDC standards for all dental professionals.

Highlights for Friday 11 April include a session on dental treatment of the older patient led by the Head of Dental Sciences at the University of Newcastle, Professor Jimmy Steele, as well as a presentation from Mike Lewis, Professor of Oral Medicine and Dean of Cardiff University. Professor Lewis will discuss how to ensure you don't miss any signs of oral cancer in your patients.

On Saturday 12 April, dental professionals involved in the treatment of periodontal

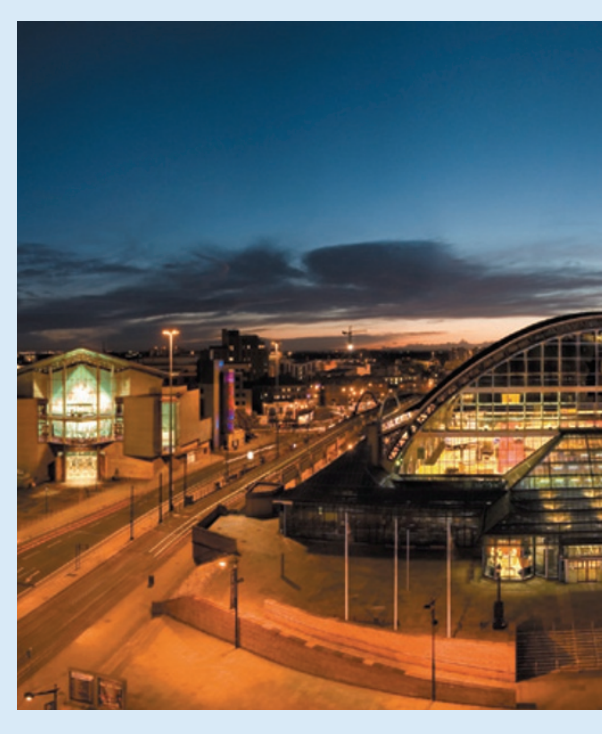

disease should make sure not to miss Professor of Periodontolgy Valerie Clerehugh's presentation examining the connection between diabetes and periodontal disease.

Further sessions including a practical periodontics presentation, a medical emergencies case study session, and a presentation by dental hygienist Donna Schembri are also included in the three day conference pass programme.

\section{In the Exhibition hall...}

The large Exhibition, free to all attendees, will be a further highlight of the event. More than 150 leading dental suppliers as well as professional services, associations and charities will be in attendance with the Innovation zone offering a chance to see the latest innovations in action.

2014 also sees the return of the popular Training Essentials and Demonstration theatres. The Demonstration theatre, hosted by the UCL Eastman Dental Institute, will offer a watch-and-learn programme of practical demonstrations on topics including conscious sedation, medical emergencies and dental photography. The Training Essentials theatre programme is based on the BDA's Training Essentials course portfolio with over 20 sessions covering core CPD subjects, regulatory updates and personal development. These will include sessions presented by some of the key professional associations for DCPs; sessions on interview techniques and leadership which will be of particular interest to practice managers, and topics of interest to the whole team ranging from decontamination and safeguarding children and vulnerable adults to managing stress and ethical practice.

\section{Get to know your peers}

There is much more to the event than what's on offer in the conference sessions and theatres. Every year the event attracts delegates representing the full range of dental-related professions. This provides a great opportunity to learn from and network with colleagues from across the country, gaining insights into to how things work in practices which may be very different to your own. In addition to the networking opportunities on offer through the day the evening programme of social events provides a great chance to let your hair down and get to know your peers. Social highlights for 2014 include Thursday evening drinks in the Exhibition hall and the Friday night party.

\section{Booking and more}

Up to 15 hours' verifiable CPD will be available for those attending. Prospective delegates can find out more and register online at www. bda.org/conference or by calling 0870166 6625. Conference Passes are available at a significantly reduced price for all DCPs - those purchasing a three-day conference pass can attend from less than $£ 50$ per day. Alternatively if any of the dentists in your practice are an Expert member of the BDA they can attend for free for the three days along with two DCPs from their team. Why not consider a team visit for ideas and inspiration that will energise your practice for the benefit of both staff and patients?

Regular programme and information updates will be available at www.bda.org/ conference and via the BDA's social media accounts.

Twitter: @thebda and @bdaevents \#bda2014 www.bda.org/facebook 